\title{
SANIDAD ESCOLAR RURAL
}

\author{
Por el Dr. ALBERTO DUARTE GONZALEZ
}

Defensa the la saiud del escolar.

1. En la primera presentación que sobre este tema hi-ciéramos a la Sociedad Chilena de Pediatría, nos propusimos plantear en forma general los distintos problemas relacionados con la defensa de la salud del escolar rural, enfocándolos desde el punto de vista de las actuales realizaciones prácticas en nuestro país. En esta segunda presentación, deseamos referirnos en detalle a algunos aspectos importantes del problem: en los cuales la responsabilidad del pediatra es considerable y cuya solución depende en gran parte de la actividad, preparación y espiritu emprendedor que este técnico dedique a su 1abor. Nuestra experiencia de dos años y medio, sirviendo et cargo de médico escolar rural, nos permitió acumular observaciones que servirán de base al presente trabajo.

2. Es evidente que uno de los fundamentos más sólides para asegurar un buen desarrollo somático y funcional en esta etapa de la infancia es el suministro de una alimentación adecuada, que ofrezca al joven organismo los materiales necesarios para su crecimiento y para una gran actividad que significa un considerable consumo de energías. No bay que esperar en modo alguno que en las condiciones de vida de nuestra población modesta pueda la familia solventar $y$ satisfacer estas necesidades de consumo. Ya hemos hablado acerca de pS:? punto en nuestra anterior presentación. Es urgente, en conrecuencia, dar la debida imporoncia a la crganización de la cantina escolar, en la cual el médico pediatra debe interver:activamentz. 
Por lo general, hay la tendencia a favorecer y preferir 13 alimentación suplementaria, que ofrece un volumen alimenticio más o menos equivalente al total de sus demandas diarias y que se dá al alumno en forma de desayuno y almuerzo. Se trata de un régimen que suple la alimentación no otorgada al niño en su bogar. Nuestro punto de vista al respecto es que esta alimentación escolar suplementaria debe reservarse exclusivamente a casos muy calificados, a través de la encuesta social, del examen médico y del informe del maestro del curso. En cambio, debe extenderse al máximo, el otorgamiento de una alimentación complementaria, sobre la base de una o dos raciones diarias de leche adicionada con un $8 \%$ de hidratos de carbono, aromatizantes y un pan de 60 gramos.

Encuestas recientes, prolijamente realizadas, apoyan este punto de vista, que tiene la ventaja de concentrar los recursos en favor de la alimentación complementaria: disminuyendo el número de niños sometidos al régimen suplementario. to cual redunda en una simplificación del trabajo. un mejor rendimiento y un alcance mayor.

3. En la defensa de la salud del niño interviene cono factor de importancia el estado del edificio escolar y de los equipos en uso. El auge de la construcción de la Sociedad de Edificios Escolares, no logra afrontar las necesidades reales de nuestras escuelas y de aquí deriva la importancia de la intervención del médico en aquéllas cuyos locales son ruinosos o insalubres. Conseguir la cooperación vecinal para llevar a la práctica todas aquellas indicaciones que el médico aconseje, a fin de salubrizar el recinto de la escuela, debe ser un objetivo que el pediatra escolar aspira alcanzar de cualquier modo. En muchas ocasiones, por cierto, es muy poco lo que se puede hacer, y esto es más frecuente tratándose del mobiliario escolar. He tenido oportunidad de visitar escuelas rurales en la zona de Curanilahue, donde se apretujaban tres niños en bancas que eran verdaderos instrumentos de suplicio y donde bay pizarrones ante los cuales hay que arrodillarse para escribir.

4. Es recomendable al médico escolar una práctica que en mi experiencia rural me dió muy buenos resultados. Me refiero a la conveniencia de visitar, en compañía de la enfermera $y$. si es posible. del maestro los hogares del alumnado. Aprovechando el ir o el venir al punto en que debía desarrollar mis actividades, me detenía en el camino para ver las condiciones de vida de aquellos niños cuya salud era motivo de preocupaciones y disgusto para la familia, el maestro y el 
médico. Es posible, de esta manera, colaborar con la flaca dádiva de algunos consejos, cuyo cumplimiento debe ser controlado inexorablemente por la enfermera. La falta de una difusión extensiva de la educación sanitaria hace que las medidas más sencillas y elementales de higiene doméstica sean desconocidas en estos hogares rurales, sometidos, por lo general, a un régimen económico sumamente precario. En este sentido, la llegada espontánea del médico y la sugetencia de éste o aquel consejo, hace nacer en estas gentes sencillas un valiosísimo espíritu de colaboración social, sin el cual es punto menos que imposible desarrollar con éxito la más mínima labor. El gran enemigo para llevar a la práctica con la frecuencia debida estas actividades es el tiempo. que para el médico rural está aliado con las distancias.

Insistimos en las ventajas de ligarse con las familias de los alumnos y en la convenjencia de incitar al maestro a realizar actividades semejantes, incluso a invitarlo a desempeñatlas en compañia. para lograr mejores resultados.

5. En el alumnado practicamos sistemáticamente la vacunación anti-variólica, con productos del Instituto Bacteriológico, que conservábamos en el frigorífico de la Casa de Socorro. En el curso del año pasado, y usando el mismo envío de igual preparación, pudimos observar reacciones desiguales en la masa de alumnos sometidos a este medio preventivo. Así, en la Escuela de La Obra, apreciamos reacciones intensas, con temperatura, malestar general, y unas placas locales del tamaño de un peso de los antiguos. En las aldeas vecinas, vacunadas en igual fecha y con el mismo producto, no hubo nada especial. La reacción familiar, que fué también intensa, la tratamos con una charla en el local de la Escuela, acompañada de películas y folletos que nos fueron proporcionados por el activo Departamento de Educación Sanitaria de la Dirección General de Sanidad.

En los sectores rurales, vale la pena practicar entre los escolares la vacunación antitífica, cuya primera aplicación no nos ofreció dificultades; pero cuya segunda logró despertar resistencia por las pequeñas molestias ocasionadas en la primera.

Estimo que la Sociedad de Pediatría debería estabiecer una pauta en esta materia de las inmunizaciones escolares, señalar sus oportunidades, conveniencias $e$ inconvenientes, a fin de poder recoger, sobre la base de procedimientos comanes. estadisticas que estimo serian muy valiosas en nuestra realidad nacional escolar. 


\section{II}

\section{Prcblemas especiales.}

6. Como la salud del niño escolar está ligada a las condiciones sanitarias que prevalecen y caracterizan la región, es muy útil al médico escolar mantenerse en contacto con las autoridades locales y con las sanitarias, a fin de poder influenciar la realización de todas aquellas medidas que estime convenientes para una efectiva defensa de la salud del niño. Por otra parte. la posibilidad de desarrollar alguila labor de orden social en beneficio de los escolares, hace recomendable este procedimiento, que en síntesis se podría definir como un estado de entente constante entre el médico escolar, las autoridades y el vecindario acomodado, que, por lo general, es sensible a aquellas solicitaciones adecuadamente planteadas. Igual recomendación es válida en el trato con las organizaciones obreras, de quienes es posible esperar una colaboración mucho mayor de aquéllas que uno podría esperar, incluyendo una acción directa sobre sus afiliados. El punto de vista es la defensa de la salud del niño sobre toda otra consideración apoyado en un trato cordial con todo el mundo.

7. Por lo general, en los sectores rurales, es muy frecuente encontrarse con maestros interinos, no normalistas, cuya preparación en materias sanitarias no es completa, de tal manera que conviene, en estos casos, organizar pequeños cursos o charlas de capacitación, en los cuales, de una manera sencilla y concreta, se les proporcione las nociones prácticas indispensables sobre estas materias. Muchas veces puede interpretarse como mala voluntad una omisión debida a ignorancia de aquellas normas que, por lo general, el médico cree son del dominio de todo el mundo. Por otra parte, muchas de las actividades médico-sociales que el médico puede propiciar, son inabordables sin la cooperación decidida del maestro, y en este entendido, lo más expedito es dotarlo de todos aquellos conocimientos necesarios de que no cuente su bagaje cultucal. Sólo es recomendable proceder con tacto y discreción para no herir susceptibilidades. He podido observar que en los sectores rurales el maestro es siempre bien recibido en los hogares de sus alumnos y establecen un clima de confianza con mucho mayor facilidad que el médico que viene resultando ser como un personaje solemne. Es, pues. una treta que da muy buenos. resultados en la práctica, el 
acompañar o hacerse acompañar con el maestro en las visitas domiciliarias.

8. Considero que nuestra escuela chilena habrá dado un paso importante en el camino de su progreso técnico el día en que implante dentro de la rutina de su labor el uso de una Ficha individual racionalmente concebida. Espero en una oportunidad próxima hacer una presentación a la Sociedad Chilena de Pediatría, acerca de estas materias cuyos puntos principales voy a esbozar a continuación. No existe en nuestras escuelas una ficha integral de cada alumno. Nuestro servicio médico escolar tiene la suya y el año pasado se ensayó una. de naturaleza pedagógica en algunas escuelas. Una Ficha Escolar racional debe, a nuestro modo de pensar. contener informaciones últiles al maestro, a la asistente social, a la enfermera y al médico escolar. Cada niño debe tener la suya y aquellas condiciones que acabo de expresar la convertirían en el más valioso instrumento acerca del desarrollo somático. psico-pedagógico y social del nin̄o $y$ de su grupo familiar. Incluyendo una selección de datos representativos, sería dable apreciar la acción de la escuela, del hogar, del médico, en fin, sería dable valorizar de unz maneta objetiva todos aquellos factores que influyen en 1 a vida del niño de edad escolar con evidente beneficio para éste, por cuanto, conociendo todos estos fenómenos, sería posible adoptar a tiempo y racionalmente, todas aquellas actitudes y determinaciones que favorecieran al máximo el progreso del niño. He tenido oportunidad de conversar sobre el asunto tanto con autoridades educacionales como médicas $y$, al mismo tiempo. con un buen número de maestros, estando tedos contestes en admitir la necesidad de llegar cuanto antes al establecimiento de este documento de inapreciable valor médico-social y pedagógico.

9. Una pregunta que el médico escolar rural no sien!pre puede contestarse, es la signiente: ¿qué hacer con los ninos cuberculosos? Una vez descubierta la enfermedad y comprobada su actividad, llega el momento de establecer el tratamiento. No se puede pensar en el hogar que, por lo $3 \mathrm{e}^{\mathrm{\prime}}$ neral, es la sede del foco infectante. Se hace, pues, necesario sacar al niño de su ambiente familiar que le representa un peligro y ubicarjo en algún sitio donde un régimen higiénicodietético y una terapéutica adecuada le ofrezca las perspectivas de una curación. Y aquí comienza uno de los aspectos. del problema. que entre nosotros dista mucho de estar resuelto, y que se suma al otro, al conjunto de medidas que es: 
preciso tomar con los otros miembros del grupo familiar in. fectado, especialmente con aquéllos ya enfermos y contagiosos. Evidentemente es éste un grave problema, que no por haber sido tratado muchas veces en este mismo recinto. deja de ser grave. Por primera providencia y para evitar mayores males. es preciso favorecer a estos niños con todas aquellas ventajas que la escuela pueda ofrecerles en cuanto a alimentacion y vestuario y alejarlos de su seno en cuanto el médico sospeche el peligro de contagio. Estimamos que la Sbciedad Chilena de Pediatría debería plantear sus puntos de vista y representar las medidas inmediatas aconsejables a adontar en la situación actual.

10. Igual cosa, aunque en menor escala, ocurre con resfecto al escolar reumático, cuyo número. sin embargo, va anmentando a medida que aumenta el volumen de niños controlados por el servicio médico escolar. Ultimamente he tenido oportunidad de leer un interesante trabajo sobte el particular. planteado en la memoria de tesis de una asistente sccial y en el que se proponían algunas medidas de realización inmediata entre nosotros, basadas en las valiosas experiencias inglesas y norteanericanas en estas materias.

11. Para terminar este capítulo, sólo quieto recalcar la conveniencia de buscar la cooperación de la industria, la agricultura y la minería que existan en el sector, como un medio de asegurar el buen éxito de la labor sanitaria que desarrolla el médico escolar rural. La ayuda, venga de donde venga, es útil. porque los tiempos que corten obligan a actuar camo en evento bélico y la salud de nuestros niños de idad escolar se encuentra en un estado deplorable. Patticaiarmente en la organización de la cantina y del ropero escolar. esta ayuda puede cobrar caracteres de especial importancia y el médico debe estimularla hasta donde sus fuerzas to permitan y las circunstancias lo aconsejen.

\section{III}

\section{Algunes datos estacísticos.}

12. En este último capítulo vamos a incluir algunas cifras representativas de los resultados que obtuvimos en el cutso del segundo año de nuestro trabajo en Puente Alto. Naturalmente no son éstas las cifras únicas que obtuviétamos; an sólo hemos presentado aquéllas que pueder sugerir algún comentario. 
a) Alumnos controlados.

Examinados

Fichados

b) Morbilidad de mayor frecuencia.

Desnutrición de primer grado .. 738

Desnutrición de segundo grado .. 279

Desnutrición de tercer grado .... 152

Total

1.169

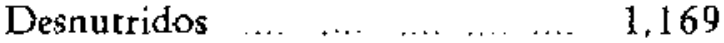

Estado nutrición normal $\ldots . . . . \quad 327$

Total

1,496

Disminución de la agudeza visual 165

Pediculosis

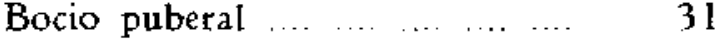

Sarna

c) Reacciones tubetculinicas.

\begin{tabular}{|c|c|c|c|c|}
\hline \multirow{2}{*}{ Ectaá } & \multicolumn{2}{|c|}{ POSITIVOS } & \multicolumn{2}{|c|}{ NEGATIVOS } \\
\hline & Total & Porcentajc & Tot:-1 & Porzenta je \\
\hline 7 & 38 & 31 & 84 & 69 \\
\hline 8 & 62 & 27 & 166 & 73 \\
\hline 9 & 47 & 25 & 137 & 75 \\
\hline 10 & 57 & 29 & 138 & 71 \\
\hline 11 & 67 & 37 & 112 & 63 \\
\hline 12 & 77 & 35 & 140 & 65 \\
\hline 13 & 55 & 39 & 84 & 61 \\
\hline 14 & 46 & 54 & 38 & 46 \\
\hline 15 & 27 & 73 & 11 & 27 \\
\hline 16 & 9 & 60 & 6 & 40 \\
\hline
\end{tabular}

Total de niños: 1,401. 


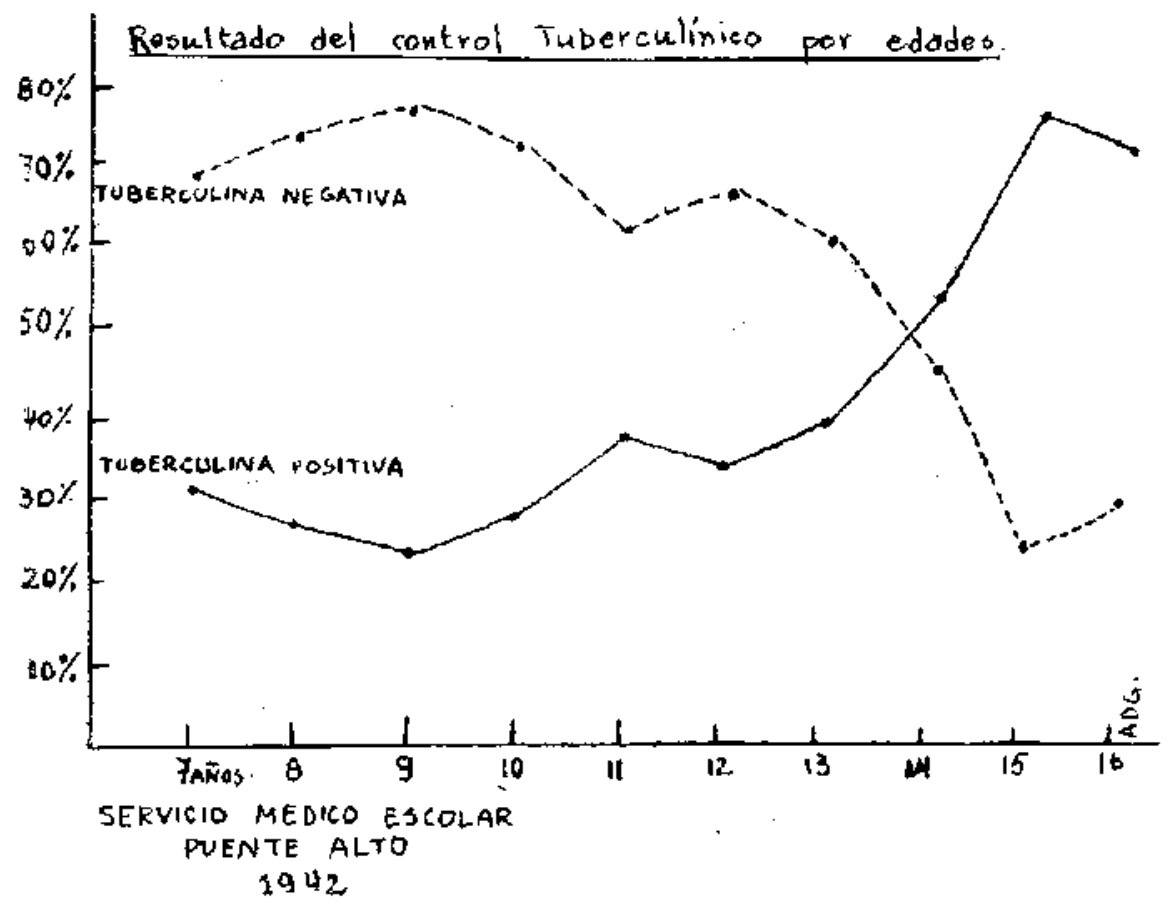

d) Radioscopias.

Cortroles. - De los 485 niños tuberculino positivos. se controló a rayos en el Sanatorio de El Peral, un $47 \%$. Las dificultades propias de la distancia y de los escasos médios de ccmunicación impidieron lograr la asistencia a rayos de todos los niños. a los que se indicó este medio de diagnóstico.

Resultados:

Sin lesión aparente $27 \%$

Complejos primarios calcificados Lesicnes activas 